\title{
A METHODOLOGICAL REVIEW OF DEMAND ANALYSIS: AN EXAMPLE OF HEALTH CARE SERVICES
}

\author{
Shiva Raj Adhikari, PhD*
}

\begin{abstract}
Demand describes the quantity of goods or services per unit of time that an individual purchases and consumes given the set of the prices and income of the consumer. The demand models based on continuous choice or discrete choice are popular in the economic literatures. Discrete choice depicts where and what kinds of health services to consume while the continuous choice portrays how much of health services to consume. Specification of the behavioural model and estimation of the parameters of the model that are interrelated tasks in discrete choice model are challenging for the researchers. Health sector data have special features like discrete nature of the data, problems of censoring, integer counts or time duration and several factors complicate attempts to obtain unbiased estimates of the impact of variables that influence demand for health care. The health care data provide wider applications of econometrics models. These models have some advantages in presenting and analyzing the choice behaviour; however, they have some limitations as well. Subsequently, the researchers are continuously interested to find and to apply appropriate models to describe the choice behaviour of the decision makers.
\end{abstract}

Key words: demand for health care services, continuous choice, discrete choice, behavioural model and econometric model

\section{INTRODUCTION}

In economic analysis, consumer behavior is expressed as a utility maximization problem subject to a given budget constraint. The demand functions are derived by solving the optimization problem. Demand describes the quantity of goods or services per unit of time that an individual purchases and consumes given the set of the prices and income of the consumer. The demand models based on continuous choice or discrete choice are popular in the economic literatures. Continuous choice model is based on neoclassical theory of consumer behavior while the relatively new discrete choice model is derived from the random utility theory. In the neoclassical theory, the utility is the function of quantities of commodity consumed, but in the discrete choice model, the utility is expressed as a function of attributes of the commodities. The neoclassical theory assumes deterministic behavior and deals with continuous (i.e., infinitely divisible) products. Calculus is used to derive many of the key results. Lancaster (1966) proposed that it is the attributes of the goods that determine the utility. Utility, therefore, can be expressed as a function of the attributes of the commodities. This theory explored the ideas of random utility theory or discrete choice theory. The individual choice behavior is intrinsically probabilistic. Discrete choice theory deals

\footnotetext{
* Mr. Adhikari is Associate Professor of Economics, Patan Multiple Campus, Tribhuvan University
} 
with a choice among a set of finite, mutually exclusive alternatives and so different techniques need to be used. However, the underlying hypotheses of random utility remain intact. In health economics, both models are equally important although discrete choice models are often used because of the nature and availability of health data. Discrete choice depicts where and what kinds of health services to consume while the continuous choice portrays how much of health services to consume.

\section{DERIVATION OF DEMAND FOR HEALTH CARE}

In the econometric modeling of demand function, the dependent variable usually reflects utilization of health care services. Observed utilization level reflects the point of intersection of demand and supply functions (market equilibrium) and the utilization of health care services reflects satisfied demand or observed demand. Sometimes, it is hard to clearly distinguish between these two functions from the observed data. In this situation, the explicit and implicit assumptions facilitate to estimate the demand function. For example, we use the term, in economics, "other things being equal" that limits the shifting factors, or supply factors, then it is possible to estimate demand functions. Similarly, the assumption of rational behaviour of the consumer reduces or ignores the possibility of supplier-induced demand in medical service.

Utilization of health care services has become a topic of widespread interest among the health economists. The determinants of demand for health care are important for a number of reasons. For example, quantification of these factors is necessary to assess medical care needs of the community and potential impact of utilization on health. Demand analysis can also indicate to the policy makers the role of consumer awareness and knowledge can play in improving the utilization of highly cost-effective health interventions or health services.

The economic models that are most relevant and commonly used in health care demand are the human capital theory and the orthodox utility theory. The first approach used for the analysis of health care demand is the inter-temporal model of utility function where utility depends upon the flow of healthy days from the stock of health and consumption of other commodities. The second approach is similar to orthodox utility theory that considers health as a choice commodity (Jack, 1999).

\section{Inter-temporal Utility Model}

Grossman (2000; 1972) has developed inter-temporal utility model, which is based on the household production framework. The model, for the first time introduced the concept that consumers do not demand medical care per se, but it is a derived demand generated through the demand for health. Individual demands health for two purposes: consumption and investment purposes. Individual can maximize his utility by generating good health and better health enhances utility or happiness. Health is 
desired as an investment good since good health enhances earning capacity. Health, thus, is both a consumption and investment good.

According to this model, the stock of health capital depreciates over time and the consumer can produce gross investments by using medical care and their own time as inputs. It is assumed that the efficiency of the production process depends on individuals' stocks of other forms of human capital, especially education. The rate of depreciation of the health stock rises with age. This implies that the stock of health falls with age. The optimal gross investment in health is positive until the last period of life. The marginal product of the stock of health diminishes as the stock increases.

Grossman's demand model has revolutionized the economic analysis of health (Leibowitz, 2004). This model has opened up the possibility of further research in the areas of health economics, for example, allocating time between income and leisure, allocating remaining leisure time on health and non health activities, allocating earned income to health and non health resources, producing health capital for use in future years. The model, however, is not free from criticisms. The questions raised by the researchers are on unrealistic assumptions of the theory. The assumptions that are often criticized are the assumption of perfect information, deterministic nature of the model, and the endogeneity of length of life, among others. Some researchers have raised serious issues on methodologies that are used in estimation of Grossman demand model. For example, Ehrlich and Chuma (1990) have claimed that if health investment functions assume constant returns to scale technology, which is used by Grossman, creates "bang-bang" problem with respect to optimal investment and health maintenance choices. Similarly, Wagstaff (1993) has argued that the empirical formulation used by Grossman is inappropriate because it fails to take into account the inherently dynamic character of the health investment process.

Grossman has used a very different theoretical paradigm to describe the determinants of health outcomes (Grossman, 2000). The empirical analysis of demand for health is also complicated because of the fact that theoretical models often involve inherently latent (unobservable) variables, which are often proxied by indicator variables. Many researchers have used the multiple indicators multiple causes (MIMIC) model, which can be estimated as linear structural relationships (LISREL). The researchers face problems of measurement of health related issues, particularly health status of the people among others. The Grossman model of demand for health, thus, has continued to be refined, modified from both the theoretical and empirical prospective. Grossman (2000) has provided a comprehensive review of this model in the theoretical and empirical ground and suggested further research areas of interest. Grossman model is more consistency with longitudinal data. In developing countries, data needed for the estimation of this model are not usually available and as a result, Grossman's models are usually applied in the developed country context. 


\section{Orthodox Utility Model}

The second approach, the static concept of demand analysis, however, is derived from Grossman's model and focuses on the estimation of the effects of price and income on utilization of medical services and health care expenditure. This approach supports the conditional utility function that depends on health outcome and consumption of goods and services other than health care, subject to health production function and budget constraint. Many different model specifications have been used in the literature for the estimation of demand for health care. The model specifications are based on: a) price is interacted with income and b) time prices are entered into the utility function rather than the budget constraint (Levin et al., 1998) that leads to two groups of results on demand for health care.

Former group of studies have shown that price elasticities are relatively inelastic as in the case of the studies conducted in Malaysia (Heller, 1982) and the Philippines (Akin et al., 1986; Schwartz et al., 1988). The later group of research studies suggest that changes in price affect quantity of health care demanded as shown by the studies conducted in Pakistan (Alderman and Gertler, 1989); Cote d'Ivoire (Dor and van der Gaag, 1987); (Gertler and van der Gaag, 1990); and Kenya (Mwabu, 1986). The later concept of demand for health care that explores the effects of access prices of health care is popular in developing countries because the policies of developing countries concentrate on how to improve the access to health care services to the population.

\section{MODELING OF DEMAND FOR HEALTH CARE}

\section{Continuous Choice Model}

Continuous choice model can analyze the intensity of consumption and can predict the quantities of health care services consumed. Health care expenditure is a measure of intensity of consumption of the services. The analysis of determinants of health expenditure can be used to derive the optimal amount of health expenditure for a society (Matteo, 2003) and can identify the factors affecting the health care expenditure. The health care expenditure model can be applied to both micro and macro-level data; however, this review focuses on the studies based on micro-level data. The studies on determinants of health expenditure are limited in developing countries due to the fact that required data are not available and modeling of the health care demand is not straight forward (Rous and Hotchkiss, 2003). Two major problems arise when attempts to analyze demand by using health care expenditure data: health expenditure data are highly skewed violating the assumption of normal distribution of the dependent variable and have presence of a large number of zero expenditures making it impossible to apply the ordinary least squared (OLS) methods (Chaze, 2005).

The literatures on health care expenditure have demonstrated that most of the studies used parametric techniques to estimate the elasticities of income and prices (Matteo, 
2003). The parametric technique assumes a functional form, normal distribution and linear relationships; however, true shape of the functional form is unknown and it is highly sensitive to the choice of the functional form. The OLS method is highly sensitive to outlier values of expenditures. Sometimes the researchers have applied weighted least squares or generalized linear model, to get rid of these problems but this does not able to solve all problems that arises from nature of health expenditure data. The log linear specifications are used to minimize these problems in estimations of demand functions, as well. Again, the researchers use log for dependent variable (log linear) to avoid the normality problems however, this technique cannot ruled out but reduces the problems (Wooldridge, 1992).The log linear form, applying natural log of both dependent and independent, facilitates the estimation of elasticities. However, from theoretical prospective, both linear and log linear specifications are inconsistent with budget constraint (Hunt-McCool, et al 1994; Deaton and Muellbauer, 1980). In this case, sum of all price and income elasticities are equal to one. We can't get the information from the estimated elasticities on luxurious goods or necessity goods or inferior goods.

Under such circumstances, relatively advanced methods, such as non-parametric and maximum likelihood techniques are used to solve these problems. Non-parametric technique is quite flexible that reduce the distribution assumptions. The techniques assume that there are non-linear relationships between health care expenditures and other economic variables, such as income. This technique is also called distribution free method that is useful to deal with both inadequacies of functional form and data with respect to outliers. These methods are consistence with budget constraint and consumer behaviour as well. Deaton and Muellbauer (1980) have developed an ideal demand system that is derived from dual of utility maximization. They derived the expenditure function, which is inverted of the indirect utility function. The dependent variable of this demand function is log of share of particular expenditure on goods or medical services to total expenditure. Hunt-McCool, et al. (1994) has estimated demand for inpatient services and outpatient services using this concept.

There are also estimators known as semi-parametric, which make some distributional assumptions, but fewer than the parametric estimators. Quintile regression, semiparametric based method, assumes a parametric specification for the qth quintile of the conditional distribution (Jones, 2000). Heteroskedaticity problem can be dealt with by estimating quantile regressions (Deaton, 1997). If the quintile regression lines are not parallel, this informs heteroskedaticity. The quintile regression estimator is popular now because it provides more efficient estimation than the least square models do (Yu et al., 2003). Quintile regression explores the information about the distribution of the dependent variable rather than the conditional mean. As we know that there are two alternative methods in econometrics to analyze the data in dependent variable (y) and given $x$ (independent variables): conditional expectation or mean, $\mathrm{E}(\mathrm{y} / \mathrm{x})$ or conditional median, $\mathrm{M}(\mathrm{y} / \mathrm{x})$. Conditional mean is conventionally popular than conditional median 
(Wooldridge, 1992). Manning et al. (1995) has applied quantile regression to estimate the demand for alcohol.

Non-linearity can arise many ways. For examples, nature of the data, truncated and censored, causes nonlinear. Maximum likelihood estimators has been continued to use as an alternative method for non-linear estimator (Cameron and Trivedi, 2005). The generalized flexible Box-Cox transformation model, which is based on maximum likelihood estimates, uses nonlinear transformations of the dependent and the explanatory variables of an OLS regression model. The Box-Cox device is also appropriate for a model with no apriori functional form has been utilized widely in econometric modeling. The researchers have claimed that the Box-Cox transformation method is appropriate for hedonic relationships as well. Hedonic expenditure relationship approaches are also applied in health care expenditure modeling, such as (Goldman and Grossman, 1978; Levy and Quigley, 1993). The Box-Cox technique has been used in strictly positive continuous value order to achieve normality. The method does not use the nonlinear transformation of dummy variables. It has some features that can solve the problems of robust estimation as well as hedonic pricing. This device, however, has some limitations, for example, this yields transformation bias (Kanamori and Takeuchi, 2006).

There are several approaches of modeling limited dependent variable like the two-part model, the Tobit model, the sample selection model, hurdle models and finite mixtures models. Two-part model comprises binary logit/probit model and OLS model. Binary logit/probit models have been applied for understanding whether individuals make any health care expenditures and OLS has been used only on the sub-sample with non-zero expenditures (log of expenditure). However, there is possibility of sample selection bias if there are many zeros (Chaze, 2005). The Tobin model assumes that the individuals choose the levels of health expenditure to maximize their welfare. Zero expenditure represents a corner solution where preferences for health care are so low that the individual is better-off spending nothing on health care.

\section{Discrete Choice Model}

Discrete choice models are typically used to obtain estimates of price elasticities of demand for health care. The left-hand side dependent variable is often measured as the incidence of use of various kinds of health facilities (for example, self care, private facility, public facility, traditional healer), though some studies utilizes continuous variable as intensity of consumption of health service to measure demand for health care.

As mentioned above, the discrete choice theory is derived from the random utility model (RUM) that expresses the rational utility theory of the consumer and a lack of information regarding the characteristics of individual or alternatives on the part of 
the researchers (Train, 2003). The researcher only observes that part of the utility that makes up from the alternatives. The alternatives are mutually exclusive, finite and exhaustive in the discrete choice model.

The indirect utility function is decomposed into two functions: one depends on observable factors and the other captures the effect of unobserved characteristics.

This can be represented by the following equation, note that Similar equation can be used in the neoclassical model however there is different in meaning of $\boldsymbol{\varepsilon}_{i}$ . In neoclassical theory, $\varepsilon_{i}$ represents measurement error, misspecification, left out variables etc. but not the utility (Varian, 1992).

$U_{i}=V_{i}+\varepsilon_{i} \quad$ Where, $\mathrm{i}=$ alternatives, $V_{i}$ is a systemic component of utility and $\varepsilon_{i}$ is a stochastic component of utility.

A decision maker faces a choice among $i$ alternatives. $U_{i}$ is the true but unobservable (latent) utility for alternative $i, V_{i}$ is the observable systematic component of utility, and $\varepsilon_{i}$ is the factor unobservable to the researcher. There are some aspects of utility that the researcher does not or cannot observe, therefore, representative utility is not equal to true utility, $U_{i} \neq V_{i} . \quad \varepsilon_{i}$ captures the factors that affect utility but are not included in $V_{i}$. Assuming that the individual can choose between two alternatives, $i$ and $j$, then the probability that alternative $i$ is chosen is given by

$\pi_{i}=\operatorname{prob}\left(U_{i}>U_{j}\right)=\operatorname{prob}\left(V_{i}+\varepsilon_{i}>V_{j}+\varepsilon_{j}\right)=\operatorname{prob}\left(V_{i}-V_{j}>\varepsilon_{j}-\varepsilon_{i}\right)$

For all, $i \neq j$

From this, it can be seen that the higher difference in the probability for choosing an alternative, the larger the difference in observed utility. Hence, observed choice is determined by the difference in utility not the level of utility per se. Due to this reason, in the process of estimation of demand for health care, one alternative should be normalized. Most of the studies have used self-care as a base category whose prices are almost zero in most cases.

Specification of the behavioural model and estimation of the parameters of the model that are interrelated tasks in discrete choice model are challenging for the researchers. The discrete choice models that are based on probability of events are relatively less informative to the researchers. Researchers are facing the problems how to take full advantages of information available from estimated results and to present the reader 
friendly manner. For this purpose, the researchers need to know at least the capabilities and limitations of the choice models.

Logit (binary as well as multinomial) and nested logit are derived under the assumptions that the error terms are independent and identically distributed (iid) and extreme value distributed. The probit model (binary as well as multinomial), on the other hand, is derived under the assumption that the unobservable part of utility is normally distributed (Train, 2003). The multinomial logit (MNL) model has a special property as it assumes independence of irrelevant alternatives (IIA). The IIA assumption is identical to the assumption of independent and identically distributed (iid) random components of each alternative. There are three properties of IIA viz: a) probabilities range from zero to one b) sum to one over alternatives and c) S- shaped function of representative utility. Unobserved factors uncorrelated over alternatives and same variance for all alternatives, known as IIA. This implies that the ratio of the probabilities of choosing one alternative over another is unaffected by the presence or absence of any additional alternatives in the choice set. Consider the ratio of the choice probabilities for two alternatives $\mathrm{j}$ and $\mathrm{k}$. The ratio of these two probabilities does not depend on any alternatives other than $\mathrm{j}$ and $\mathrm{k}$. Since the ratio is independent from alternatives other than $j$ and $k$, it is said to be independent from irreverent alternatives.

The cross elasticity is the same for all alternative due to IIA assumptions. MNL, therefore, is not useful to estimate cross elasticity among the alternatives. The nested logit (NL) model is a generalization of the MNL model that allows for a particular pattern of correlation in unobserved utility (that is differences in cross-elasticities of substitution across alternatives). An NL model is appropriate when the set of alternatives faced by a decision maker can be partitioned into subsets, called nests. Theoretically, the multinomial probit model does not impose IIA and is attractive; however, it has some practical limitations. The practical complexity not only makes it difficult to obtain the partial effects on the response probabilities, but also makes maximum likelihood infeasible for more than about five alternatives (Wooldridge, 2002).

Ordered logit model uses categorical variable where respondents are asked to report a particular category and where there is a natural ordering such as excellent health, good health, fair or poor health . It seems reasonable to assume that excellent health is better than good, which is better than fair, which is better than poor, for everyone in the population. An econometric model that can be used to deal with ordered categorical variables is the ordered probit model. Mixed logit is based on the assumption that the unobserved portion of utility consists of a part that follows any distribution specified by the researcher plus a part that is iid extreme value. With probit and mixed logit, the integral does not have a closed form and is evaluated numerically through simulation. All studies have demonstrated that prices of health services do affect the demand for health care; however, the size of the impacts may differ with model specifications and the nature of data. 
Health sector data have special features like discrete nature of the data, problems of censoring, integer counts or time duration and several factors complicate attempts to obtain unbiased estimates of the impact of variables that influence demand for health care. The health care data provide wider applications of econometrics models that are binary logit/probit, multinomial logit/probit, nested logit, ordered logit, mixed logit, Tobit, negative binomial, finite mixture, among o thers. These models have some advantages in presenting and analyzing the choice behaviour; however, they have some limitations as well. Subsequently, the researchers are continuously interested to find and to apply appropriate models to describe the choice behaviour of the decision makers.

Scott et al. (1996) conducted a research to explore the associations between outcome variables and the consumer's characteristics using three set of binary choice: decision to follow up; to prescribe; and to perform or to order a diagnostic test utilizing national health survey data 1989/90 of Australia. Yip et al. (1998) estimated the utilization of health care using multinomial logit model to estimate the factors that influenced consumers choice of medical provider in the three tired health care system in rural china. Gertler and van der Gaag (1990) and Mwabu et al. (1993), a few of them, have investigated impact of user fee in choice of health care services using nested logit and multinomial logit models.

Cameron et al. (1988) have developed a count data model to analyze the choices of insurance plans and health care providers using household survey data of Australia. Dow (1995) has compared the specification of the models: parsimonious non-linear, linear and flexible using Cote d'Ivoire health care data and found that results are sensitive to choices of model specification and flexible model was considered more appropriate to get robust estimation of health care demand. Similarly, Bolduc et al. (1996) has estimated demand for health care using three different models: multinomial logit, independent multinomial probit and multinomial probit using data from rural villages of Africa. They have found similar result as suggested by Dow (1995) about the impact of model specification on results and questioned previous results of using multinomial logit specifications. Kenkel (1990) has applied ordered logit model in categorical measures of health related information of US national health interview survey to estimate the effect of socioeconomic variables to health information and demand for health care. Recently, Borah (2006) has applied a very sophisticated and more powerful model, mixed logit model, on health care data collected in India.

For the empirical analysis of demand for health care, self-reported illness and first consultation with health care providers are used as the primary variables, although questions have been raised about the reliability and validity of these variables. Selfreported illness may produce biased results as the perception of illness may be different for poor and non-poor individuals and perception about a disease affects the choice of health care services and providers (Akin et al., 1998). Akin et al. (1998) have nicely 
described the possible bias in the estimation of health care demand and suggested solving this problem by controlling for bias in sample selection. They used symptoms of the diseases in order to determine ill respondents.

Another potential problem in the estimation of demand is that the consumers may consult more than one provider for treatment for the same episode (Gertler et al., 2000); therefore, analysis based on the first visit to health care provider does not capture the complex decision-making behaviour of the people. The demand analysis with multilevel approach could be extremely useful in this situation (Jack, 1999).

\section{CONCLUSIONS}

Demand analysis of health care is determined by approaches of demand, the nature of data, econometric models. The longitudinal data requires inter-temporal utility model. Orthodox utility model therefore is more popular then inter- temporal utility model in developing countries. Continuous choice model can analyze the intensity of consumption; however, discrete choice is used to explain the likelihood of using different kinds of services and whether or not to consume certain types of care. The discrete choice cannot describe the intensity of consumption of the services and can predict the quantities of health care services consumed. Due to discrete nature of the data, discrete choice models are more popular than continuous choice model. Indeed, the existing literatures on discrete choice model deal with first consultation of health care providers, however; in reality, the consumers may make several visits to find the standard health care. The demand analysis based on first consultation of health care providers does not capture path of decision making process and underestimates the total cost of health care and its consequences. It needs to develop the multi-stage demand model that can capture the sequential demand for health care. The reviews reach to the conclusions that the debates on theories as well as empirical estimations of demand for health care are continuing, consequently, the various arguments encourage the researchers to experiment and develop new, more-appropriate approaches for the estimation of health care demand.

\section{References}

Akin, J. S. Guilkey, D. K. Hutchinson, P. L. \& Mcintosh, M. T. (1998). Price Elasticities of Demand for Curative Health Care With Control for Sample Selectivity on Endogenous Illness: An Analysis for Sri Lanka. Health Econ. 7: 509-531

Akin, J. Griffin, C. Guilkey, D. \& Popkin, B. (1986). The demand for primary health care services in the Bicol Region of the Philippines. Economic Development and Cultural Change, 34(4): 755-782.

Alderman, H. \& Gertler, P. (1989). Substitutability of public and private health care for the treatment of children in Pakistan. Living Standards Measurement Study Working Paper 57, Washington: The World Bank,

Bolduc, D. Lacroix, G. Muller, C. (1996). The choice of medical providers in rural Benin: a comparison of discrete choice models. Journal of Health Economics,15: 477-498 
Borah, B. J. (2006). A mixed logit model of health care provider choice: analysis of NSS data for rural India. Health Economics, 15 (9): 915 - 932

Cameron, A. C. \& Trivedi, P. K. (2005). Microeconometrics Methods and Applications. Cambridge University Press

Cameron, A. C. Trivedi, P. K. Milne, F. \& Piggott, J. (1988). A microeconomic model of the demand for health care and health insurance in Australia. Review of Economic Studies, $55,85-106$

Chaze, J. (2005). Assessing household health expenditure with Box-Cox censoring models Health Econ 14: 893-907

Deaton, A. \& Muellbaur, J. (1980). An almost ideal demand system. American economic review 70:312-326

Deaton, A. (1997). The analysis of household surveys: a microeconometric approach to development policy. Published for the World Bank by Johns Hopkins University Press.

Dor, A. Gertler, P. \& van der Gaag. J. (1987). Non-price Rationing and the Choice of Medical Care Providers in Rural Cote d'Ivoire. Journal of Health Economics, 6 (4): 291-304.

Dow, W. (1995). Discrete choice estimation of price-elasticities: the benefits of a flexible behavioral model of health care demand. Rand Working Paper Series, 95-20:1-45.

Ehrlich, I. \& Chuma, H. (1990). A model of the demand for longevity and the value of life extensions. Journal of Political Economy, 98:761-782

Gertler, P. J. Rose, E. \& Glewwe, P. (2000). Health Designing Household Survey Questionnnaires for Developing countries: Lesson from 15 years of the Living Standard Measurement Survey. etd by Margaret Ghosh and Paul Glewwe, Chapter 8, World Bank

Gertler, P. and van der Gaag, J. (1990). The willingness to pay for medical care: Evidence from two developing countries. Baltimore and London: Johns Hopkins University Press for the World Bank.

Goldman, F. \& Grossman, M. (1978). The demand for pediatric care: a hedonic approach. Journal of Political Economy, 86, (2)

Grossman, M. (1972). On the concept of health capital and the demand for health. Journal of Political Economy, 80:223-255

Grossman, M. (2000). Health human capital model. Handbook of Health economics, Culyer and Newwhouse (Ed). ELSEVIER, New York

Heller, P. S. (1982). A Model of the Demand for Medical and Health Services in Peninsular Malaysia. Social Science and Medicine, 16:267-84

Hunt-McCool, J. Kiker, B. F. Ng, Y. C. (1994). Estimates of the demand for medical care under different functional forms. Journal of Applied Econometrics, 9 (2): 201-218

Jack, W. (1999). Principle of Health Economics in Developing Countries. The World Bank Washington D.C.

Jones, A. M. (2000). Health Econometrics. In Handbook of Health Economics, vol. 1A. ed. A. J. Culyer and J. P. Newhouse, pp. 265-344. Amersterdam: Elsevier.

Kanamori, T. \& Takeuchi, I. (2006). Conditional mean estimation under asymmetric and heteroscedastic error by linear combination of quantile regressions. Computational Statistics \& Data Analysis, 50:3605 - 3618 
Kenkel, D. (1990). Consumer health information and the demand for medical care. The Review of Economics and Statistics, 72 (4): 587-595

Lancaster, K. (1966). A New Approach to Consumer Theory. Journal of Political Economy, 74, 132-157.

Lavy, V. \& Quigley, T. M. (1993). Willingness to pay for the quality and intensity of medical care low income household in Ghana. Living Standard working paper 94 World Bank

Leibowitz, A. A. (2004). The demand for health and health concerns after 30 years. Journal of Health Economics, 23: 663-671

Levin, A. Rahman, M. A. Quayyam, Z. Subrata R. et al. (1998). Demand for Child Curative care in two Rural Thanas of Bangladesh: Effects Income and Women's Employment. Working paper No 116 International Centre for Diarrhoeal disease research, Bangladesh

Manning, W. G. Blumberg, L. \& Moulton, L. H. (1995). The demand for alcohol: differential response to price. Journal of Health Economics, 14:123-148

Matteo, L. D. (2003). The Income Elasticity of Health Care Spending: A Comparison of Parametric and Nonparametric Approaches. The European Journal of Health Economics, 4 (1): 20-29.

Mwabu, G. Ainsworth, M. \& Nyamete, A. (1993). Quality of Medical Care and Choice of Medical Treatment in Kenya: An Empirical Analysis. Journal of Human Resources, 28 (4): 838-62.

Mwabu, G. (1986). Health care financing in Kenya: a simulation of welfare effects of user fees. Social Science and Medicine, 22: 763-767

Rous, J. J. \& Hotchkiss, D. R. (2003). Estimation of the determinants of household health care expenditures in Nepal with controls for endogenous illness and provider choice. Health Economics, 12: 431-451

Schwartz, J.B. Akin, J. \& Popkin, B. (1988). Price and income elasticities for modern health care: the case of modern infant delivery in the Philippines. World Bank Economic Review, 2(1): 49-76.

Scott, A. Shiell, I. \& King, M. (1996). Is General Practitioner Decision Making Associated With Patient Socio-Economic Status? Soc. Sci. Med., 42, (1) :35-46

Train, K. E. (2003). Discrete choice method with simulation, Cambridge University Press, UK

Varian, H. (1992). Advanced Microeconomic Analysis, Third edition, WW Norton and company New York

Wagstaff, A. (1993). The demand for health: An empirical reformulation of the Grossman model. Health Economics, 2:189-198.

Wooldridge, J. M. (1992). Some alternative to the Box - Cox regression model. International Economic Review, 33

Wooldridge, J. M. (2002). Econometrics analysis of cross sectional and panel data The MIT press Cambridge

Yip, C. W. Wang, H. \& Liu, Y. (1998). Determinants of patient choice of medical provider: a case study in rural China. Health Policy and Planning, 13(3): 311-322

Yu, K. Lu, Z. \& Stander, J. (2003). Quantile Regression: applications and current research areas. The Statistician, 52(3), 331-350. 